\title{
Polyvalent Detection of Members of the Genus Potyvirus by Molecular Hybridization Using a Genus-Probe
}

\author{
Jesús A. Sánchez-Navarro, ${ }^{\dagger}$ Christopher N. Cooper, and Vicente Pallás
}

First and third authors: Department of Molecular and Evolutionary Plant Virology, Instituto de Biología Molecular y Celular de Plantas (IBMCP) (UPV-CSIC), Universitat Politécnica de Valencia, Ingeniero Fausto Elio s/n, 46022 Valencia, Spain; and second author: Georgia Institute of Technology, School of Chemistry \& Biochemistry, Atlanta 30332.

Accepted for publication 7 June 2018.

\begin{abstract}
The use of a unique riboprobe named polyprobe, carrying partial sequences of different plant viruses or viroids fused in tandem, has permitted the polyvalent detection of up to 10 different pathogens by using a nonradioactive molecular hybridization procedure. In the present analysis, we have developed a unique polyprobe with the capacity to detect all members of the genus Potyvirus, which we have named genus-probe. To do this, we have exploited the capacity of the molecular hybridization assay to cross-hybridize with related sequences by reducing the hybridization temperature. We observed that sequences showing a percentage similarity of $68 \%$ or higher could be detected with the same probe by hybridizing at

50 to $55^{\circ} \mathrm{C}$, with a detection limit of picograms of viral RNA comparable to the specific individual probes. According to this, we developed several polyvalent polyprobes, containing three, five, or seven different 500-nucleotide fragments of a conserved region of the NIb gene. The polyprobe carrying seven different conserved regions was able to detect all the 32 potyviruses assayed in the present work with no signal in the healthy tissue, indicating the potential capacity of the polyprobe to detect all described, and probably uncharacterized, potyviruses being then considered as a genus-probe. The use of this technology in routine diagnosis not only for Potyvirus but also to other viral genera is discussed.
\end{abstract}

Plants are affected by a large number of viruses, which in many cases cause significant economic losses, compromising the viability of agricultural industries. Effective management of viral diseases requires an integrated approach addressed to prevent or delay the progress of the infection. The use of healthy plants represents one of the main measures to manage viral diseases by reducing the initial source of inoculum. Accordingly, rapid and reliable routine virus testing procedures is a critical step in their control (Jones et al. 2006). Traditional detection methods include bioassays with indicator plants and serological methods such as the enzyme-linked immunosorbent assay (ELISA), although the molecular detection techniques (RT-PCR, microarrays, molecular hybridization, etc.) have been incorporated in the routine diagnosis of plant viruses (Jeong et al. 2014).

During recent years, plant virus detection procedures have been addressed to get the simultaneous detection of the main pathogens affecting a crop, in order to save time, labor, and overall cost. Several strategies have been used for simultaneous detection of plant viruses. For PCR-derived assays, two main approaches have been used according to the use of a cocktail of primers targeting different pathogens (multiplex RT-PCR) or a polyvalent primer pair (polyvalent PCR) that is able to drive the amplification of a conserved region (James et al. 2006). However, the detection limit of the multiplex RT-PCR technique appears to be affected when more than six different pathogens are detected (SanchezNavarro et al. 2005) and the polyvalent primers are often compromised by the lack of conserved regions. In the case of the genus Potyvirus, the presence of a very conserved region in the NIb gene has permitted the detection of virus isolates from all major groups of the genus, including uncharacterized species (Zheng et al. 2010). The incorporation of the DNA-microarray technology has

†Corresponding author: J. A. Sánchez-Navarro; E-mail: jesanche@ibmcp.upv.es

*The $\boldsymbol{e}$-Xtra logo stands for "electronic extra" and indicates that two supplementary figures are published online.

(c) 2018 The American Phytopathological Society incremented significantly the simultaneous detection and identification of multiple plant viruses and (or) virus subgroups (Barba and Hadidi 2011; Bystricka et al. 2005). However, the difficulty of adapting the array technology for routine screening of large numbers of samples and the high costs associated with equipment required have compromised its incorporation in routine plant virus analysis. The serological assay has been also adjusted to polyvalent detection of 33 (Jordan and Hammond 1991) or 14 (Liu et al. 2015) potyvirus species by using broad-spectrum monoclonal antibody $(\mathrm{MAb})$ that recognize a conserved core region of the potyvirus coat proteins. In the latter case, the authors indicate that the MAb could detect many potyviruses in infected plants, but also that different binding affinities were observed in some infected samples.

Multiple detection by using the nonisotopic molecular hybridization technique was addressed first by a cocktail of the specific single probes in the hybridization solution, allowing the polyvalent detection of the different plant viruses affecting ornamental (Sanchez-Navarro et al. 1999), horticultural (Minutillo et al. 2012; Saldarelli et al. 1996), and stone fruits crops (Saade et al. 2000); and second, by using a unique riboprobe, called "polyprobe", that contains partial nucleic acid sequences of different viruses (Aparicio et al. 2009; Herranz et al. 2005; Peiró et al. 2012) or viroids (Cohen et al. 2006; Lin et al. 2011; Zhang et al. 2012) cloned in tandem. The polyprobe has proved the simultaneous detection of six different viruses (Herranz et al. 2005) or up to eight viroids (Cohen et al. 2006; Torchetti et al. 2012), eight viruses plus two viroids (Peiró et al. 2012) or three different pathogens comprised of virus, viroid, and bacteria (Zamora-Macorra et al. 2015), with the same detection limit as the single assay. Recently, an octamer of 32nucleotide sequence derived from the central conserved region of viroids in the genus Coleoviroid was used to develop a universal probe allowing the detection at least of four coleus viroids (Jiang et al. 2013).

In the present work, we have explored the potential capacity of the polyprobe technology to develop a universal probe with the property to detect all members of a specific viral genus, in this case the genus Potyvirus. The cross hybridization observed at 50 to $55^{\circ} \mathrm{C}$ 
between sequences sharing an identity of $68 \%$ or higher was used to design several polyprobes, carrying in tandem different 500nucleotide fragments of the conserved NIb gene, with the capacity to cross hybridize with all potyvirus species available in the database. A polyprobe carrying seven different conserved regions was able to detect all the 32 potyviruses assayed in the present work, revealing the potential capacity of this technology to be applied at the genus-probe (GP) level.

\section{MATERIALS AND METHODS}

Computing analysis. The phylogenetic analysis was performed with all potyviruses for which the complete nucleotide sequence is available in the database. The phylogenetic analyses were inferred in a multistep process: in the first step, the sequences were aligned using the CLUSTAL W program (Higgins et al. 1994) to generate, in a second step, the neighbor-joining phylogenetic trees, using the JTT model, implemented in the MEGA7: Molecular Evolutionary Genetics Analysis version 7.0 for bigger datasets (Kumar et al. 2016). Third, the statistical reliability of the constructed trees was assessed by the bootstrap method based on 10,000 pseudoreplicates.

The more conserved region observed in the potyvirus alignment, covering 500 nucleotides of the NIb gene (Supplementary Fig. S1) was used to estimate the identity value between all the analyzed potyvirus sequences. To do this, we used the MatGAT (Matrix Global Alignment Tool) application that generates similarity/identity matrices for DNA sequences (Campanella et al. 2003).

To identify the equivalent conserved region in the rest of viruses assigned to the family Potyviridae, the seven selected conserved regions from Lettuce mosaic virus (LMV), Watermelon mosaic virus (WMV), Potato virus Y (PVY), Pepper veinal mottle virus (PVMV), Plum pox virus (PPV), Sweet potato feathery mottle virus (SPFMV), and Tobacco etch virus (TEV) were aligned with all species of the corresponding family Potyviridae, for which the complete nucleotide sequence is available in the database, using the CLUSTAL W program. The selected regions were also used to estimate the identity value with the MatGAT application.

Plant materials. The plant tissue was obtained from the Leibniz Institute DSMZ-German Collection of Microorganism and Cell Cultures (https://www.dsmz.de/home.html) or from the Mediterranean Agroforestal Institute at the Polytechnic University of Valencia (http://www.upv.es/iam/ingles/bienvenida.htm). Total nucleic acid extraction was performed using $0.1 \mathrm{~g}$ of lyophilized or fresh leaf tissue using the silica capture extraction protocol (MacKenzie et al. 1997) that renders total nucleic acids. The extracted nucleic acids were stored at $-80^{\circ} \mathrm{C}$ until use. Alternatively, healthy and infected tissue were homogenized with 5 volumes of cold extraction buffer (50 mM sodium citrate, $5 \mathrm{mM}$ EDTA, $\mathrm{pH} 8.5)$ and directly applied $(1 \mu \mathrm{l})$ onto nylon membranes (Sanchez-Navarro et al. 1998).

Synthesis of cDNA clones. Reverse transcription and PCR reactions were carried out using specific primers (Table 1), containing the $5^{\prime}$ and $3^{\prime} \mathrm{XhoI}$ and SalI restriction sites, respectively. PCR products were digested with both restriction enzymes and extracted from the agarose gel. The purified PCR fragments were inserted in the pBluescript $\mathrm{SK}(+)$ plasmid, previously digested with the XhoI enzyme and dephosphorylated. The incorporation of the purified PCR fragment into the $\mathrm{pSK}+$ plasmid in the right orientation allowed the inactivation of the original XhoI site, present in the pSK+ plasmid, by the compatible SalI site. This permits the use of the new $5^{\prime}$ proximal XhoI for the synthesis of the riboprobe or the incorporation of a new PCR fragment (Peiró et al. 2012). Using this strategy, we introduced seven cDNA fragments in the $\mathrm{pSK}+$ corresponding to the partial sequences of the following viruses: LMV, WMV, PVY, PVMV, PPV, SPFMV, and TEV. We generated three polyprobes that differed in the number of viral sequences incorporated. Thus, GP3, GP5, and GP7 contained three (PPV-SPFMV-TEV), five (PVY-PVMV-PPV-SPFMVTEV), and seven (LMV-WMV-PVY-PVMV-PPV-SPFMV-TEV) viral sequences, respectively.

Synthesis of the digoxigenin-labeled riboprobes and hybridization procedure. For the synthesis of the riboprobes, $1 \mu \mathrm{g}$ of the corresponding plasmid was linearized with XhoI restriction enzyme, purified by phenol-chloroform extraction and precipitated with ethanol. The linearized plasmid was used to synthesize the riboprobe as described previously (Mas et al. 1993; Pallás et al. 1998). $1 \mu \mathrm{l}$ of the total nucleic acids preparations (undiluted or serially diluted in extraction buffer), were directly applied onto positively charged nylon membranes (Roche Diagnostics $\mathrm{GmbH}$, Manheim, Germany), air dried and cross-linked by UV crosslinker $\left(700 \times 100 \mu \mathrm{J} / \mathrm{cm}^{2}\right)$. Prehybridizations and hybridizations with the riboprobes were conducted as described previously, with the only difference of the temperature selected for the hybridization (Pallás et al. 1998; Sanchez-Navarro et al. 1999). All riboprobes were used at the same concentration in the hybridization solution $(20 \mathrm{ng} / \mathrm{ml})$. Chemiluminescent detection using CDP-start reagent as substrate was performed as recommended by the manufacturer (Roche Diagnostics GmbH, Manheim, Germany). Films were exposed for $30 \mathrm{~min}$.

Estimation of the detection limit of the hybridization assays. For the estimation of the detection limit of the single or the three polyprobes, the seven DNA fragments cloned in the pSK+ were PCR amplified using the corresponding antisense primer and the reverse primer. The resultant PCR fragment contains the

TABLE 1. Primer pairs used in the amplification of the genus-probes

\begin{tabular}{|c|c|c|c|c|}
\hline Primer name & Nucleotide sequence $\left(5^{\prime}-3^{\prime}\right)^{\mathrm{a}}$ & Target viral species & $\begin{array}{c}\text { Expected } \\
\text { fragment (bp) }\end{array}$ & $\begin{array}{l}\text { Accession number and } \\
\text { location in the genome }\end{array}$ \\
\hline 2847-s & CACACTCGCGGTAAGTTTGGAGTGTGGAA & Lettuce mosaic virus, LMV & 496 & X97704 \\
\hline 2848-As & CACAGTCGACGTCATAGCTAGCACAACCAT & & & $7961-8457$ \\
\hline 2869-s & CACACTCGAGAAGGGAATTTGGAAYGGTTC & Watermelon mosaic virus, WMV & 466 & EU660589 \\
\hline 2870-As & CACA $\overline{\text { GTCGACTTGTCAACGACTGTAGATGG }}$ & & & $7882-8348$ \\
\hline 2845-s & CACACTCGAGATTTGGAACGGATCATTGAA & Potato virus $Y, \mathrm{PVY}$ & 472 & AJ890346 \\
\hline 2846-As & CACAGTCGACACCATGAGAGAATTATCCAC & & & $7510-7982$ \\
\hline 2865-s & CACAC̄TCGAGGTAAACTTGGGATTTGG & Pepper veinal mottle virus, PVMV & 479 & DQ645484 \\
\hline 2866-As & CACA $\overline{\text { GTCGACCATGAGAGTGTTATC }}$ & & & $7530-8009$ \\
\hline 2871-s & CACACTCGAGGAAAGAAAGGAGTGTGGAATGG & Plum pox virus, $\mathrm{PPV}$ & 498 & KU508427 \\
\hline 2872-As & CACAGTCGCGTCATTGCCAAAATAACCAT & & & $7495-7993$ \\
\hline 2873-s & CACACTCGAGATGGGATACAAAGGTCTYTGGAA & Sweet potato feathery mottle virus, SPFMV & 493 & KU511268 \\
\hline 2874-As & CACA $\overline{\text { GTCGACGCTAACACAACCATAAGTGT }}$ & & & $8563-9056$ \\
\hline 2861-s & CACA $\overline{C T C G A G G A A A G C T G G G A A T T T G G ~}$ & Tobacco etch virus, TEV & 479 & DQ986288 \\
\hline 2862-As & CACA $\overline{\overline{G T C G A C}}$ CATGAGTGTGTTGTC & & & $7468-7947$ \\
\hline
\end{tabular}

a Restriction sites of the XhoI and SalI are underlined.

b Numbers refer to the corresponding nucleotide of the sequence available in the indicated accession number of the GenBank database. 


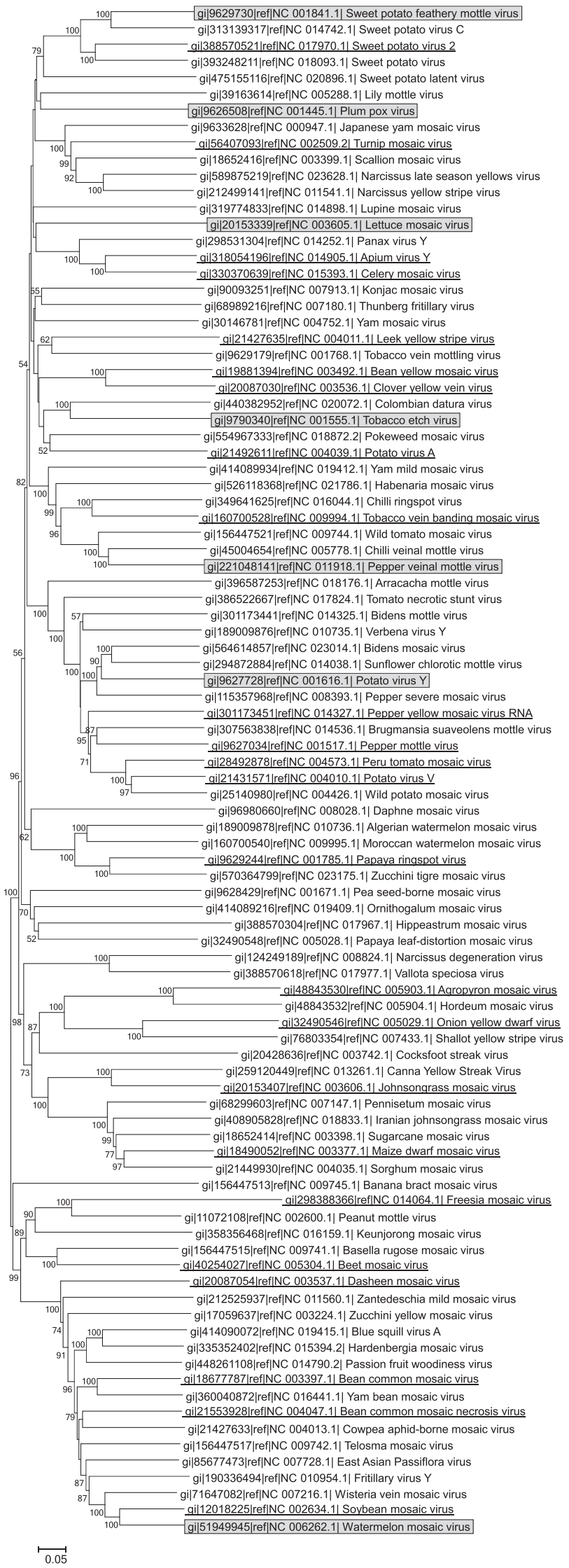

Fig. 1. Phylogenetic trees of the 94 potyviruses for which the complete sequence is known. Trees were developed using nucleotide sequences of the complete genome and inferred by the minimum-evolution method. Values at the nodes are bootstrap values based on 10,000 pseudoreplicates. Nodes with bootstrap support $<50 \%$ are not indicated. Sequences in gray boxes were used for the synthesis of the genus-probes. Sequences underlined correspond to the potyvirus used for the hybridization detection using the genus-probes. corresponding potyvirus clone plus the T3 promoter. The amplicons were purified from agarose gel and then used directly for the synthesis of unlabeled transcripts complementary to the corresponding dig-RNA probes. Known amounts of the free transcripts were serially diluted (fivefold) in sterile water since previous results showed similar detection limit $(\mathrm{pg} / \mu \mathrm{l}$ of viral RNA) for the no-radioactive molecular hybridization procedure when the dilutions were performed in sterile water (Peiró et al. 2012) or heathy tissue (Sanchez-Navarro et al. 1996, 1998). The dilutions were applied directly onto nylon membranes and the dot-blot hybridization was conducted as described previously.

\section{RESULTS}

Design of the polyprobes and analysis of the crosshybridization. In order to get representative common sequences that would allow us to design a potential polyprobe at the genus level we performed a phylogenetic analysis using all potyvirus sequences from 94 species. The resultant phylogenetic tree grouped all viruses into different clusters supported with significant bootstrap values (Fig. 1). We selected the following seven potyviruses that cover the full spectrum of disparate sequences (viral names in gray boxes, Fig. 1): LMV, WMV, PVY, PVMV, PPV, SPFMV, and TEV. Sequence alignment of all the 94 potyvirus species revealed a highly conserved region of $500 \mathrm{nt}$ in the NIb gene. The corresponding regions of the seven selected potyvirus were cloned separately in a bacterial plasmid to generate the individual probes but also in tandem to obtain three different polyprobes carrying three (PPV, SPFMV, and TEV), five (PVY, PVMV, PPV, SPFMV, and TEV), or seven (LMV, WMV, PVY, PVMV, PPV, SPFMV, and TEV) viral sequences (Fig. 2A). MatGAT analysis of the seven selected sequences revealed a percent identity that ranged between 64.8 and $72.5 \%$ (Fig. 2B).

In the next step, we analyzed the capacity of each individual riboprobe to cross-hybridize to the rest of the selected sequences. To do this, we synthesized complementary transcripts of the seven selected sequences that were serially diluted (1:5) and applied on

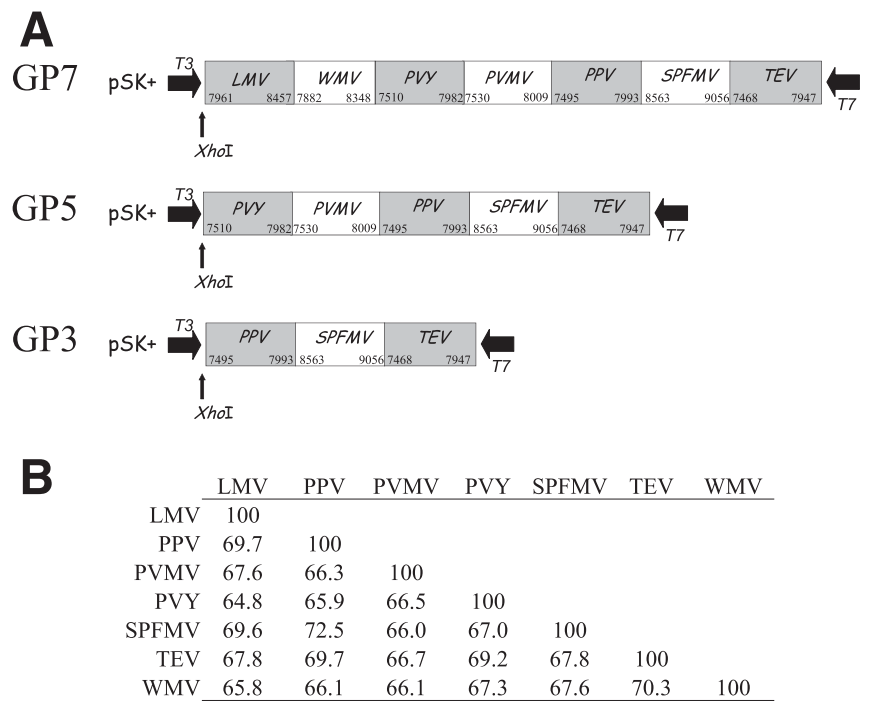

Fig. 2. Schematic representation of the different genus-probes (GP) 3, 5, and 7 clones introduced in the $\mathrm{pSK}+$ plasmid. A, The corresponding virus fragments are indicated by a box in which the numbers represent the corresponding nucleotide of the database sequences: X97704 (Lettuce mosaic virus, LMV), EU660589 (Watermelon mosaic virus, WMV), AJ890346 (Potato virus $Y$, PVY), DQ645484 (Pepper veinal mottle virus, PVMV), KU508427 (Plum pox virus, PPV), KU511268 (Sweet potato feathery mottle virus, SPFMV), and DQ986288 (Tobacco etch virus, TEV). The XhoI restriction site used either to synthesize the riboprobe with the T7 RNA polymerase or to insert additional cDNA probes is indicated. B, Schematic representation of the identity percentage estimated by MatGAT between the sequences used for the genusprobes LMV, PPV, PVMV, PVY, SPFMV, TEV, and WMV. 
A

PPV probe

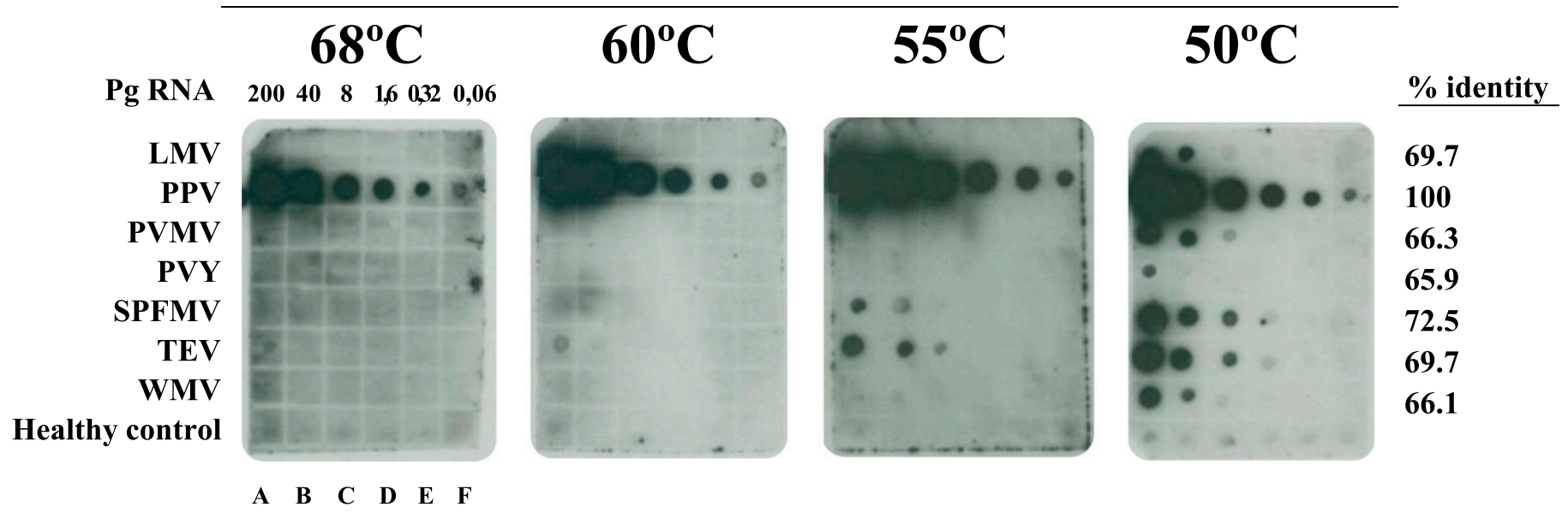

\begin{tabular}{rcccc} 
& \multicolumn{4}{c}{ PPV probe } \\
\cline { 3 - 6 } B & $\left(68^{\circ} \mathrm{C}\right)$ & $\left(60^{\circ} \mathrm{C}\right)$ & $\left(55^{\circ} \mathrm{C}\right)$ & $\left(50^{\circ} \mathrm{C}\right)$ \\
\cline { 3 - 6 } LMV & 69.7 & 69.7 & 69.7 & 69.7 \\
PPV & 100 & 100 & 100 & 100 \\
PVMV & 66.3 & 66.3 & 66.3 & 66.3 \\
PVY & 65.9 & 65.9 & 65.9 & 65.9 \\
SPFMV & 72.5 & 72.5 & 72.5 & 72.5 \\
TEV & 69.7 & 69.7 & 69.7 & 69.7 \\
WMV & 66.1 & 66.1 & 66.1 & 66.1 \\
Healthy control & - & - & - & + \\
\cline { 2 - 5 }
\end{tabular}

\begin{tabular}{rccccccc}
\multicolumn{7}{c}{ C } & \multicolumn{7}{c}{ Probe $\left.\mathbf{( 5 5}^{\mathbf{0}} \mathbf{C}\right)$} \\
\cline { 3 - 9 } & LMV & PPV & PVMV & PVY & SPFMV & TEV & WMV \\
LMV & 100 & 69.7 & 67.6 & 64.8 & 69.6 & 67.8 & 65.8 \\
PPV & 69.7 & 100 & 66.3 & 65.9 & 72.5 & 69.7 & 66.1 \\
PVMV & 67.6 & 66.3 & 100 & 66.5 & 66.0 & 66.7 & 66.1 \\
PVY & 64.8 & 65.9 & 66.5 & 100 & 67.0 & 69.2 & 67.3 \\
SPFMV & 69.6 & 72.5 & 66.0 & 67.0 & 100 & 67.8 & 67.6 \\
TEV & 67.8 & 69.7 & 66.7 & 69.2 & 67.8 & 100 & 70.3 \\
WMV & 65.8 & 66.1 & 66.1 & 67.3 & 67.6 & 70.3 & 100 \\
Healthy control & - & - & - & - & $+/-$ & - & - \\
\hline
\end{tabular}

Fig. 3. Evaluation of the cross hybridization between the seven potyvirus sequences indicated in Figure 2. A, Influence of the temperature in the cross hybridization between the Plum pox virus (PPV) probe and the rest of the indicated potyvirus sequences. Known amounts of the positive transcripts corresponding to the sequences indicated in Figure 2 were applied on nylon membranes. For the healthy control, 100 ng of total RNA extracted from melon (A), cucumber (B), Nicotiana benthamiana (C), tomato (D), chrysanthemum (E), and gynura (F) were applied. Replicas of the same membrane were hybridized with the PPV riboprobe, complementary to the sequence indicated in Figure 2 at $68,60,55$, and $50^{\circ} \mathrm{C}$, respectively. Numbers on the top of the left panel indicate the picograms of transcripts applied on the membrane, while numbers on the right side indicate the identity percentage estimated by the MatGAT program (Campanella et al. 2003) between the PPV sequence and the rest of the potyvirus sequences indicated in Figure 1. B, Summary of the results obtained in A. Numbers represent the identity percentage between the PPV sequence and the rest of the potyvirus sequences, while the colors indicate the lowest amount for which transcripts showed hybridization with the PPV probe. The colors shown online are blue (200 pg), dark blue (40 pg), green ( $8 \mathrm{pg})$, yellow $(1.6 \mathrm{pg})$, orange $(0.32 \mathrm{pg})$, and red $(0.06 \mathrm{pg})$. White indicates no hybridization signal. C, Schematic representation of the hybridization observed with the seven individual potyvirus probes. Replicas of the membrane described in A were hybridized at $55^{\circ} \mathrm{C}$ with the indicated probes. Numbers represent the corresponding identity percentage estimated by MatGAT program, while the colors represent the lowest amount of transcripts showing hybridization with the corresponding probe, as indicated in B. Films were exposed for $15 \mathrm{~min}$. 
nylon membranes, together with total RNA extracted from several healthy tissues (Fig. 3). Replicas of the same membrane were hybridized first with the PPV riboprobe at different hybridization temperatures, to evaluate the effect of such parameter in the crosshybridization (Fig. 3A). We observed no cross-reaction when the hybridization was performed at $68^{\circ} \mathrm{C}$. However, the reduction of 8 degrees during the hybridization assay $\left(60^{\circ} \mathrm{C}\right)$ was sufficient to start to see cross-hybridization with the TEV sequence at high concentration $(200 \mathrm{pg} / \mu \mathrm{l})$, meanwhile the reduction of another 5 $\left(55^{\circ} \mathrm{C}\right)$ or $10\left(50^{\circ} \mathrm{C}\right)$ degrees was sufficient to detect two (TEV, SPFMV) or all sequences at different concentrations. In the case of the hybridization performed at $50^{\circ} \mathrm{C}$, we also observed a weak signal in the negative controls (100 ng of total RNA extracted from healthy tissue). Accordingly, we evaluated the cross-hybridization of the remaining riboprobes at $55^{\circ} \mathrm{C}$ (Fig. 3C). In general, we observed that sequences with an identity percentage below $65 \%$ with the corresponding probe were not detected at $55^{\circ} \mathrm{C}$ but also that sequences with such percentage higher than $67 \%$ were all detected, except the PPV probe that rendered negative results with LMV, which shared $69.7 \%$ identity. Between 65 and $67 \%$ identity, we observed different behaviors suggesting that other factors influence the cross-hybridization (e.g., the size of the identical regions, the percentage of cytosine or guanine nucleotides, etc.).

Next, we evaluated the cross-reactivity of the three polyprobes (GP3, GP5, and GP7) (Fig. 4). For this purpose, we used replicas of the same membrane described in Figure 3 that were hybridized at $50^{\circ} \mathrm{C}$, since no cross-hybridization was observed with the negative controls at this temperature. First, we observed that the shorter polyprobe carrying only three sequences (GP3: PPV, SPFMV, and TEV) was able to detect the seven potyvirus sequences in which the lower detection limit corresponded to the PVMV transcripts at $8 \mathrm{pg} / \mu \mathrm{l}$ (Fig. 4). The inclusion of another two viral sequences in the GP5 polyprobe (PVY, PVMV, PPV, SPFMV,

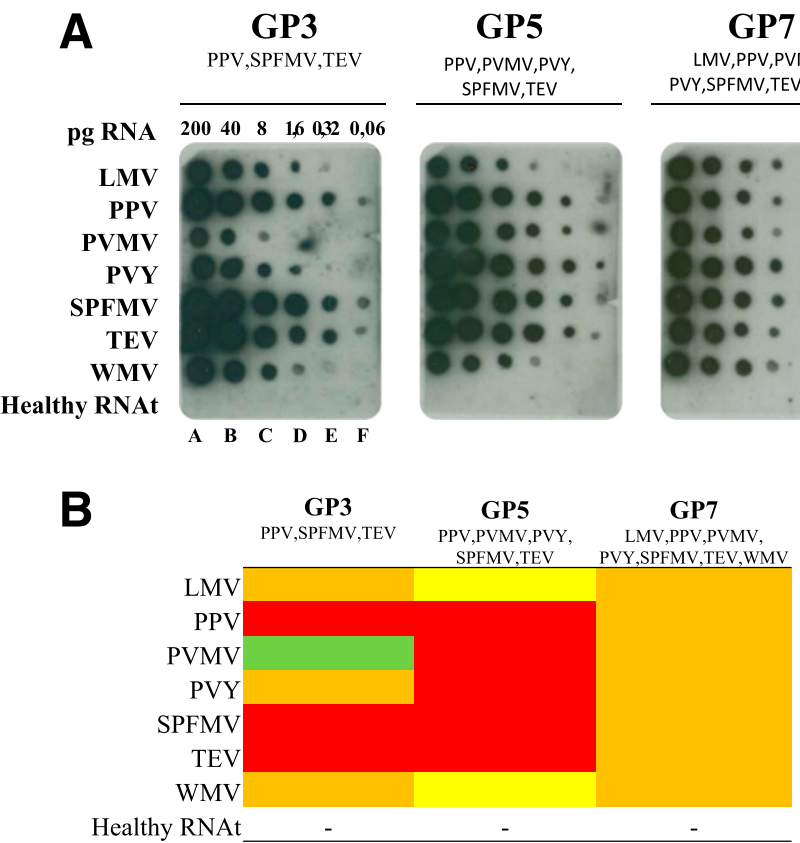

Fig. 4. Evaluation of the cross hybridization between the seven potyvirus sequences and genus-probes (GP) 3, 5, and 7. A, Replicas of the membrane described in Figure $3 \mathrm{~A}$ were hybridized with the indicated genus-probe at $50^{\circ} \mathrm{C}$. For the healthy control, $100 \mathrm{ng}$ of total RNA extracted from melon (A), cucumber (B), Nicotiana benthamiana (C), tomato (D), chrysanthemum (E), and gynura (F) were applied. Numbers on the top of the left panel indicate the picograms of transcripts applied on the membrane. Films were exposed for 15 min. B, Summary of the results obtained in A. The colors indicate the lowest amount of transcripts showing hybridization with the corresponding genusprobe. The colors shown online are blue $(200 \mathrm{pg})$, dark blue $(40 \mathrm{pg})$, green $(8 \mathrm{pg})$, yellow $(1.6 \mathrm{pg})$, orange $(0.32 \mathrm{pg})$, and red $(0.06 \mathrm{pg})$. White indicates no hybridization signal. and TEV) allowed the detection of all seven viral sequences with lower detection limits, at least for the sequences present in the polyprobe. Thus, we observed positive hybridization signal for all sequences included in the GP5 until a concentration of $0.06 \mathrm{pg} / \mu \mathrm{l}$, while the other two sequences not present in the polyprobe were detected until a concentration of $1.6 \mathrm{pg} / \mu \mathrm{l}$, five times less sensitive than the GP3. Apparently, the enlargement of the polyprobe has a slight negative effect in the detection limit of the heterologous sequences. Finally, we hybridized the membrane with the GP7 polyprobe and we obtained the same detection limit for all analyzed viruses, corresponding to $0.32 \mathrm{pg} / \mu \mathrm{l}$. As observed for the GP5, the increment of the size of the polyprobe affected the detection limit, reducing five times the best signals obtained with GP3 or GP5.

In silico analysis of the capacity of genus-probe to detect all potyviruses available in the database and other members of the family Potyviridae. According to the results obtained, sequences showing an identity percentage of $68 \%$ or higher with the selected probes, could be detected by cross-hybridization. To identify how many potyvirus sequences could be potentially hybridized with the cloned potyvirus sequences, we performed a MatGAT analysis (Campanella et al. 2003) using the equivalent region of the 94 potyvirus species used for the phylogenetic analysis (Supplementary Fig. S2). The results showed that all potyvirus species presented an identity percentage of $68 \%$ or higher with two or more of the seven selected sequences. Only Onion yellow dwarf virus, with a percentage of $69.3 \%$, showed such identity with only PPV. In addition, we observed that the majority of the sequences presented identity percentages of $70 \%$ or higher with any of the selected sequences. Only Daphne mosaic virus, Habenaria mosaic virus, Hordeum mosaic virus, Onion yellow dwarf virus, Ornithogalum mosaic virus, and Vallota speciosa virus presented identity percentages below $70 \%$. Also, we observed that the 94 potyvirus species could be theoretically detected with the smaller genus-probe of GP3, since all sequences presented an identity percentage higher than $68 \%$ with any of the PPV, TEV, and SPFMV cloned fragments.

To identify if other members of the family Potyviridae could be potentially detected with the seven selected potyvirus sequences, the equivalent regions from 27 species representatives of the seven genera of the family Potyviridae, except potyvirus, were subjected to a MatGAT analysis (Campanella et al. 2003) to determine the identity percentage. The results obtained revealed that all viruses, except rymovirus, presented an identity percentage below $65 \%$, suggesting that they should be not detected with any of the different probes assayed herein. In the case of rymovirus, the three species analyzed showed identity percentage of $68 \%$ or higher with one or more of the seven selected sequences and, thus, susceptible of being detected by the genus-probes.

Analysis of field samples by nonradioactive nucleic acids spot hybridization (NASH). Finally, we evaluated the capacity of the three genus-probes to detect heterologous potyviruses or other viral species of the family Potyviridae by analyzing 49 different field samples, including different hosts, for the presence of 32 potyvirus species or 7 viral species assigned to the genus Bymovirus, Ipomovirus, Rymovirus, and Tritimovirus (Table 2). First, it should be mentioned that the infected starting material was lyophilized or fresh tissue proportionated by the German Collection of Microorganisms and Cell Cultures (DSMZ) or the Mediterranean Agroforestal Institute of the Polytechnic University of Valencia. The samples were extracted using the silica protocol (MacKenzie et al. 1997) but also with a fast protocol in which the tissue is homogenized with citrate buffer and directly applied onto the membrane (Sanchez-Navarro et al. 1998, 1999). First, we observed no hybridization signal with any of the eight healthy hosts analyzed, in spite of the hybridization being performed at $50^{\circ} \mathrm{C}$. The 32 potyviruses and the 2 rymoviruses were detected by NASH with the three genus-probes except for PVMV that rendered negative signal with GP3. Interestingly, GP3 presents the most unfavorable situation for PVMV detection since its identity percentage with 
the three cloned sequences present in GP3 is around 66 to $68 \%$ (Fig. 3). On the other hand, we observed that Onion yellow dwarf virus, which theoretically could be detected only with the PPV clone (identity percentage of $69.3 \%$ ), was detected with all three genus-probes. In addition, Ryegrass mosaic virus was clearly detected with GP3 and GP5, in spite of the fact that the higher identity percentage in both probes corresponded to the PPV cloned sequence at $67.2 \%$. When the plants were analyzed using the fast citrate buffer protocol, we observed that $90.2 \%$ of silica positives ( 83 out 92 ) were correctly detected. We also observed two samples that were positive by citrate buffer extraction and negative by silica extraction, using the GP3 and GP5 probes (samples 30 and 34 , Table 2). These results could indicate differences in the viral titer associated to the extraction protocol used but we cannot discard other effects derived of the starting material (lyophilized) or the host (Nicotiana benthamiana or Cucurbita pepo) that could interfere with the detection procedure.

\section{DISCUSSION}

In the last few years, a significant effort has been made to develop strategies for simultaneous detection of multiple plant viruses. Although PCR-based approaches have received special attention, molecular hybridization assay represents an attractive methodology for the detection of plant viruses since it is accurate, sensitive ( $\mathrm{pg} / \mu \mathrm{l}$ of viral RNA), robust, and very powerful for large screening with a reduced cost (James et al. 2006; Pallás et al. 2011, 2017 for review). Previous works showed that this technology allows multiple detection of plant viruses by a cocktail of specific probes or by a unique probe carrying the different viral fragments fused in

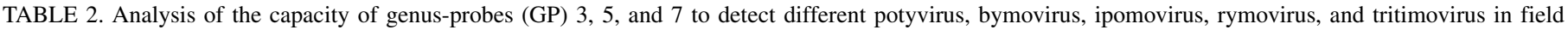
samples by nucleic acids spot hybridization (NASH) ${ }^{\mathrm{a}}$

\begin{tabular}{|c|c|c|c|c|c|c|c|}
\hline \multirow[b]{2}{*}{ Virus } & \multirow[b]{2}{*}{ Acronym } & \multirow[b]{2}{*}{ Genus } & \multirow[b]{2}{*}{ Source $^{b}$} & \multirow[b]{2}{*}{ Host } & \multicolumn{3}{|c|}{ NASH (silica/citrate buffer) } \\
\hline & & & & & GP3 & GP5 & GP7 \\
\hline Carrot virus $Y$ & CarVY & Potyvirus & UPV & Daucus carota & $+/+$ & $+/+$ & $+/+$ \\
\hline Onion yellow dwarf virus & OYDV & Potyvirus & UPV & Allium сера & $+/-$ & $+/-$ & $+/+$ \\
\hline Turnip mosaic virus & TuMV & Potyvirus & UPV & Lactuca sativa & $+/+$ & $+/+$ & $+/+$ \\
\hline Bean common mosaic necrosis virus & BCMNV & Potyvirus & DSMZ & Phaseolus vulgaris & $+/+$ & $+/+$ & $+/+$ \\
\hline Bean common mosaic virus & BCMV & Potyvirus & DSMZ & Phaseolus vulgaris & $+/+$ & $+/+$ & $+/+$ \\
\hline Beet mosaic virus & BtMV & Potyvirus & DSMZ & Nicotiana benthamiana & $+/+$ & $+/+$ & $+/+$ \\
\hline Johnsongrass mosaic virus & JGMV & Potyvirus & DSMZ & Zea mays & $+/+$ & $+/+$ & $+/+$ \\
\hline Leek yellow stripe virus & LYSV & Potyvirus & DSMZ & Chenopodium quinoa & $+/+$ & $+/+$ & $+/+$ \\
\hline Pepper mottle virus & PepMoV & Potyvirus & DSMZ & Nicotiana tabacum & $+l^{*}$ & $+/+$ & $+/+$ \\
\hline Peru tomato mosaic virus & PTV & Potyvirus & DSMZ & Nicotiana tabacum & $+l^{*}$ & $+/+$ & $+/+$ \\
\hline Potato virus $A$ & PVA & Potyvirus & DSMZ & Nicotiana occidentalis & $+/+$ & $+/+$ & $+/+$ \\
\hline Potato virus $V$ & PVV & Potyvirus & DSMZ & Nicotiana benthamiana & $+/+$ & $+/+$ & $+/+$ \\
\hline Potato virus $Y$ & PVY & Potyvirus & DSMZ & Nicotiana tabacum & $+/ *$ & $+/+$ & $+/-$ \\
\hline Soybean mosaic virus & SMV & Potyvirus & DSMZ & Nicotiana benthamiana & $+/+$ & $+/+$ & $+/ *$ \\
\hline Tobacco vein banding mosaic virus & TVBMV & Potyvirus & DSMZ & Nicotiana benthamiana & $+/+$ & $+/+$ & $+/+$ \\
\hline Maize dwarf mosaic virus & MDMV & Potyvirus & DSMZ & Zea mays & $+/+$ & $+/+$ & $+/+$ \\
\hline Dasheen mosaic virus & DsMV & Potyvirus & DSMZ & Nicotiana benthamiana & $+/+$ & $+/+$ & $+/+$ \\
\hline Apium virus $Y$ & ApVY & Potyvirus & DSMZ & Ami majus & $+/+$ & $+/+$ & $+/+$ \\
\hline Pepper yellow mosaic virus & PepYMV & Potyvirus & DSMZ & Nicotiana tabacum & $+l^{*}$ & $+/+$ & $+/+$ \\
\hline Sweet potato virus 2 & SPV-2 & Potyvirus & DSMZ & Nicotiana benthamiana & $+/+$ & $+/+$ & $+/+$ \\
\hline Bean yellow mosaic virus & BYMV & Potyvirus & DSMZ & Nicotiana benthamiana & $+/+$ & $+/+$ & $+/+$ \\
\hline Carrot thin leaf virus & CTLV & Potyvirus & UPV & Daucus carota & $+/+$ & $+/+$ & $+/+$ \\
\hline Celery mosaic virus & CeMV & Potyvirus & UPV & Apium graveolens & $+/ \mathrm{nt}$ & $+/ \mathrm{nt}$ & $+/ \mathrm{nt}$ \\
\hline Clover yellow vein virus & ClYVV & Potyvirus & UPV & Phaseolus vulgaris & $+/ \mathrm{nt}$ & $+/ \mathrm{nt}$ & $+/ \mathrm{nt}$ \\
\hline Freesia mosaic virus & FreMV & Potyvirus & UPV & Freesia & $+/+$ & $+/+$ & $+/-$ \\
\hline Papaya ringspot virus & PRSV & Potyvirus & UPV & Citrullus lanatus & $+/ \mathrm{nt}$ & $+/ \mathrm{nt}$ & $+/ \mathrm{nt}$ \\
\hline Tobacco etch virus & TEV & Potyvirus & UPV & Nicotiana tabacum & $+/+$ & $+/+$ & $+/+$ \\
\hline Tobacco etch virus & TEV & Potyvirus & UPV & Physalis floridana & $+/+$ & $+/+$ & $+/+$ \\
\hline Lettuce mosaic virus & LMV & Potyvirus & DSMZ & Chenopodium quinoa & $-/+$ & $-1+$ & $+/+$ \\
\hline Pepper veinal mottle virus & PVMV & Potyvirus & DSMZ & Nicotiana benthamiana & $-1-$ & $+/+$ & $+/+$ \\
\hline Sweet potato feathery mottle virus & SPFMV & Potyvirus & DSMZ & Nicotiana benthamiana & $+/+$ & $+/+$ & $+/+$ \\
\hline Tobacco etch virus & TEV & Potyvirus & UPV & Nicotiana tabacum & $+/+$ & $+/+$ & $+/+$ \\
\hline Watermelon mosaic virus & WMV & Potyvirus & DSMZ & Cuсurbita реро & $-1+$ & $-1+$ & $+/+$ \\
\hline Plum pox virus & PPV & Potyvirus & $\mathrm{Lab}$ & Prunus domestica & $+/ \mathrm{nt}$ & $+/ \mathrm{nt}$ & $+/ \mathrm{nt}$ \\
\hline Barley yellow mosaic virus & BaYMV & Bymovirus & DSMZ & Hordeum vulgare & $-1-$ & $-1-$ & $-1-$ \\
\hline Ugandan cassava brown streak virus & UCBSV & Ipomovirus & DSMZ & Manihot esculenta & $-1-$ & $-1-$ & $-1-$ \\
\hline Cucumber vein yellowing virus & CVYV & Ipomovirus & UPV & Cucumis sativus & $-1-$ & $-1-$ & $-1-$ \\
\hline Sweet potato mild mottle virus & SPMMV & Ipomovirus & DSMZ & Nicotiana tabacum & $-1-$ & $-1-$ & $-1-$ \\
\hline Agropyron mosaic virus & AgMV & Rymovirus & DSMZ & Triticum aestivum & $+/+$ & $+/+$ & $+/+$ \\
\hline Ryegrass mosaic virus & RGMV & Rymovirus & DSMZ & Lolium multiflorum & $+/+$ & $+/+$ & $+/+$ \\
\hline Brome streak mosaic virus & BrSMV & Tritimovirus & DSMZ & Hordeum vulgare & $* /-$ & $* /-$ & $* /-$ \\
\hline Healthy control & & & $\mathrm{Lab}$ & Cucumis melo & $-/ \mathrm{nt}$ & $-/ \mathrm{nt}$ & $-/ \mathrm{nt}$ \\
\hline Healthy control & & & Lab & Cucumis sativus & $-/ \mathrm{nt}$ & $-/ \mathrm{nt}$ & $-/ \mathrm{nt}$ \\
\hline Healthy control & & & Lab & Nicotiana benthamiana & $-1-$ & $-1-$ & $-1-$ \\
\hline Healthy control & & & Lab & Solanum lycopersicum & $-/ \mathrm{nt}$ & $-/ \mathrm{nt}$ & $-/ \mathrm{nt}$ \\
\hline Healthy control & & & $\mathrm{Lab}$ & Chrysanthemum & $-/ \mathrm{nt}$ & $-/ \mathrm{nt}$ & $-/ \mathrm{nt}$ \\
\hline Healthy control & & & $\mathrm{Lab}$ & Gynura aurantiaca & $-/ \mathrm{nt}$ & $-/ \mathrm{nt}$ & $-/ \mathrm{nt}$ \\
\hline Healthy control & & & $\mathrm{Lab}$ & Nicotiana tabacum & $-1-$ & $-1-$ & $-1-$ \\
\hline Healthy control & & & UPV & Arabidopsis thaliana & $-1-$ & $-1-$ & $-1-$ \\
\hline
\end{tabular}

a All samples were extracted with the silica and the citrate buffer protocols. The hybridization was performed at $50^{\circ} \mathrm{C}$.,,+- and $*$ correspond to positive, negative, and uncertain results, respectively. nt, no tissue available.

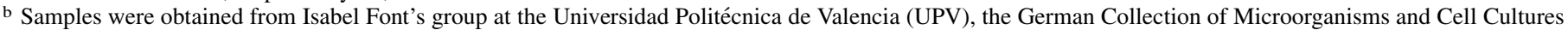
(DSMZ), or our laboratory (Lab). 
tandem called a polyprobe. The polyprobes permit the detection of several pathogens with comparable detection limit to the individual probes (Herranz et al. 2005), although with long polyprobes (e.g., 10 probes in tandem or more) a reduction of the hybridization temperature is required (Peiró et al. 2012). A challenge of this strategy has been its adaptation by generating a polyvalent polyprobe able to detect all species within a genus, named genus-probe. To answer this question we have selected the genus Potyvirus for three reasons: (i) it is one of the largest groups of plant viruses including 146 species (Revers and Garcia 2015), (ii) potyviruses affect many species which are economically important (Scholthof et al. 2011), and (iii) some other diagnosis assays have been adjusted for the detection of a broad spectrum of potyviruses with varied success (Chen et al. 2001; Hsu et al. 2005; Jordan and Hammond 1991; Liu et al. 2015; Wei et al. 2009). To obtain the genus-probe we have used the versatility of the molecular hybridization that permits the detection of closely related sequences by reducing the hybridization temperature. Thus, we selected the more conserved region, representing $500 \mathrm{nt}$ of the NIb gene, of seven potyviruses distributed along the genus phylogenetic tree and we observed that cross-hybridization occurs at $55^{\circ} \mathrm{C}$ (single probes) or $50^{\circ} \mathrm{C}$ (polyprobes) when the target sequences share $68 \%$ or higher identity percentage with the probe, meanwhile negative hybridization signal was obtained when the percentage was below $65 \%$. We observed some exceptions to these rules (e.g., LMV is not detected by PPV probe sharing 69\%) suggesting that factors other than the identity percentage are important in the cross-hybridization. In this sense, the presence of large identical regions, the percentage of cytosine and guanines or the probe mismatches, among others, are critical factors to take into account (Kessler 2000). In these hybridization conditions, there were no positive signals in the different healthy controls used, opening the applicability of this assay for routine diagnosis. According with the identity percentage required for cross-hybridization, the three genus-probes described herein have the capacity to detect the 94 potyvirus species analyzed. However, we observed some negative results (samples 29, 30, or 33) using the GP3 that were positive by GP5 or GP7. Apparently, the presence of more conserved fragments with the capacity to hybridize with a target sequence increments the detection limit of the GP. In our hands, we were able to detect $100 \%$ of potyviruses analyzed ( 32 species in 34 samples), representing a comparable (33 species in 55 samples) (Jordan and Hammond 1991) or a significant increment from previous approaches using broad-spectrum MAb (14 species) (Liu et al. 2015) or polyvalent primer pairs that ranged between $100 \%$ (23 species in 40 samples) (Zheng et al. 2010), 80\% (32 out 40 samples corresponding to 21 species out 23) (Pappu et al. 1993), or $50 \%$ (20 out 40 samples corresponding to 15 species out 23) (Gibbs and Mackenzie 1997). We also observed a positive hybridization signal with the two rymovirus analyzed, while no hybridization was observed with the rest of the viral species assigned to bymovirus, ipomovirus, or tritimovirus. Interesting, the two rymovirus AgMV and RGMV (samples 39, 40) plus BrSMV (tritimovirus, sample 41) and BaYMV (bymovirus, sample 25) were also detected by RTPCR using the universal potyviruses NIb primers (Zheng et al. 2010) (data not shown), indicating high conserved sequences in this region in the family Potyviridae. Positive hybridization signal was also observed in some species that share only an identity percentage close to the estimated limit of $68 \%$ for cross-hybridization, with one of the conserved fragments of the genus-probe (e.g., Onion yellow dwarf virus or Ryegrass mosaic virus). In addition, the possibility to use a fast protocol, which detected $90 \%$ of positive samples analyzed by NASH, together with the robustness of the methodology that permits the detection of species with significant nucleotide sequences variability or even uncharacterized potyviruses and the reduced time and cost make the nonradioactive hybridization of using a genus-probe a very suitable approach for the routine diagnosis of potyvirus in large surveys. Currently, the use of a broad-spectrum MAb PTY1 (Jordan and Hammond 1991), combined with a direct tissue extract procedure, represents a valuable tool for diagnostic and screening applications for the detection of aphid-transmissible potyviruses, although it is not known how large the spectrum of viruses that could be detected by the MAb PTY1. The genus-probe developed in this work anticipates that all potyviruses can be broadly detected (identity percentage of $68 / 69 \%$ or higher). Furthermore, this technology presents the advantage to be easily updated by introducing new sequences of interest (e.g., new potyviruses, etc.). In addition, the use of this new genus-probe, in conjunction to other molecular techniques that permit the identification of the corresponding potyvirus species (e. g., degenerate primer-based RT-PCR or HTS methods, etc.), could be a very good approach to detect any potyvirus isolate, previously described or uncharacterized. Finally, the observation that the genus-probe could detect also members of the genus Rymovirus, opens the possibility to design a genus-probe against the family Potyviridae. An open question related to the genus-probe technology is the size of the conserved regions to be introduced in the polyprobe. In the present work, we have selected fragments of around $500 \mathrm{nt}$ but further analysis will be addressed to delimitate the minimal size of the conserved regions that still are able to crosshybridize.

\section{ACKNOWLEDGMENTS}

We thank L. Corachán for her excellent technical assistance and I. Font and A. O. Alfaro, from the Mediterranean Agroforestal Institute at the Polytechnic University of Valencia, for provide part of the potyvirusinfected field samples. This work was supported by grant BIO2017-88321$\mathrm{R}$ from the Spanish Direccion General de Investigacion Cientifica y Tecnica (DGICYT-MINECO).

\section{LITERATURE CITED}

Aparicio, F., Soler, S., Aramburu, J., Galipienso, L., Nuez, F., Pallás, V., and López, C. 2009. Simultaneous detection of six RNA plant viruses affecting tomato crops using a single digoxigenin-labelled polyprobe. Eur. J. Plant Pathol. 123:117-123.

Barba, M., and Hadidi, A. 2011. DNA microarrays and other future trends in detection and typing of viruses, viroids and phytoplasmas. Pages 363-372 in: Virus and Virus-Like Diseases of Pome and Stone Fruits. A. Hadidi, M. Barba, T. Candresse, and W. Jelkmann, eds. American Phytopathological Society Press, St. Paul, MN.

Bystricka, D., Lenz, O., Mraz, I., Piherova, L., Kmoch, S., and Sip, M. 2005. Oligonucleotide-based microarray: A new improvement in microarray detection of plant viruses. J. Virol. Methods 128:176-182.

Campanella, J. J., Bitincka, L., and Smalley, J. 2003. MatGAT: An application that generates similarity/identity matrices using protein or DNA sequences. BMC Bioinformatics 4:29.

Chen, J., Chen, J., and Adams, M. J. 2001. A universal PCR primer to detect members of the Potyviridae and its use to examine the taxonomic status of several members of the family. Arch. Virol. 146:757-766.

Cohen, O., Batuman, O., Stanbekova, G., Sano, T., Mawassi, M., and Bar-Joseph, M. 2006. Construction of a multiprobe for the simultaneous detection of viroids infecting citrus trees. Virus Genes 33:287-292.

Gibbs, A., and Mackenzie, A. 1997. A primer pair for amplifying part of the genome of all potyvirids by RT-PCR. J. Virol. Methods 63:9-16.

Herranz, M. C., Sanchez-Navarro, J. A., Aparicio, F., and Pallas, V. 2005. Simultaneous detection of six stone fruit viruses by non-isotopic molecular hybridization using a unique riboprobe or 'polyprobe'. J. Virol. Methods 124:49-55

Higgins, D., Thompson, J., Gibson, T., Thompson, J. D., Higgins, D. G., and Gibson, T. J. 1994. CLUSTAL W: Improving the sensitivity of progressive multiple sequence alignment through sequence weighting, position-specific gap penalties and weight matrix choice. Nucleic Acids Res. 22:4673-4680.

Hsu, Y. C., Yeh, T. J., and Chang, Y. C. 2005. A new combination of RT-PCR and reverse dot blot hybridization for rapid detection and identification of potyviruses. J. Virol. Methods 128:54-60.

James, D., Varga, A., Pallas, V., and Candresse, T. 2006. Strategies for simultaneous detection of multiple plant viruses. Can. J. Plant Pathol. 28:16-29.

Jeong, J., Ju, H., and Noh, J. 2014. A review of detection methods for the plant viruses. Res. Plant Dis. 20:173-181.

Jiang, D., Hou, W., Sano, T., Kang, N., Qin, L., Wu, Z., Li, S., and Xie, L. 2013. Rapid detection and identification of viroids in the genus Coleviroid using a universal probe. J. Virol. Methods 187:321-326. 
Jones, R. A. 2006. Control of plant virus diseases. Adv. Virus Res. 67:205-244.

Jordan, R., and Hammond, J. 1991. Comparison and differentiation of potyvirus isolates and identification of strain-, virus-, subgroup-specific and potyvirus group-common epitopes using monoclonal antibodies. J. Gen. Virol. 72:25-36.

Kessler, C. 2000. Overview on factors influencing nucleic acid hybridization. Pages 437-442 in: Nonradioactive Analysis of Biomolecules. C. Kessler, ed. Springer, Berlin, Heidelberg.

Kumar, S., Stecher, G., and Tamura, K. 2016. MEGA7: Molecular evolutionary genetics analysis version 7.0 for bigger datasets. Mol. Biol. Evol. 33:1870-1874.

Lin, L., Li, R., Mock, R., and Kinard, G. 2011. Development of a polyprobe to detect six viroids of pome and stone fruit trees. J. Virol. Methods 171:91-97.

Liu, H.-L., Lin, W.-F., Hu, W.-C., Lee, Y.-A., and Chang, Y.-C. 2015. A strategy for generating a broad-spectrum monoclonal antibody and soluble single-chain variable fragments against plant potyviruses.. Appl. Environ. Microbiol. 81:6839-6849.

MacKenzie, D. J., McLean, M. A., Mukerji, S., and Green, M. 1997. Improved RNA extraction from woody plants for the detection of viral pathogens by reverse transcription-polymerase chain reaction. Plant Dis. 81:222-226.

Mas, P., Sánchez-Navarro, J. A., Sánchez-Pina, M. A., and Pallás, V. 1993. Chemiluminescent and colorigenic detection of cherry leaf roll virus with digoxigenin-labeled RNA probes. J. Virol. Methods 45:93-102.

Minutillo, S. A., Mascia, T., and Gallitelli, D. 2012. A DNA probe mix for the multiplex detection of ten artichoke viruses. Eur. J. Plant Pathol. 134: 459-465.

Pallás, V., Faggioli, F., Aparico, F., and Sanchez-Navarro, J. A. 2011. Molecular hybridization techniques for detecting and studying fruit tree viruses and viroids. Pages 333-339 in: Virus and Virus-Like Diseases of Pome and Stone Fruits. A. Hadidi, M. Barba, T. Candresse, and W. Jelkmann, eds. American Phytopathological Society, St. Paul, MN.

Pallás, V., Más, P., and Sánchez-Navarro, J. 1998. Detection of plant RNA viruses by nonisotopic Dot-blot hybridization. Pages 461-468 in: Plant Virology Protocols. G. Foster and S. Taylor, eds. Humana Press, New York.

Pallás, V., Sánchez-Navarro, J. R., Kinard, G., and Di Serio, F. 2017. Molecular hybridization techniques for detecting and studying viroids. Pages 369-379 in: Viroids and Satellites. A. Hadidi, R. Flores, J. W. Randles, and P. Palukaitis, eds. Academic Press Inc., London.

Pappu, S. S., Brand, R., Pappu, H. R., Rybicki, E. P., Gough, K. H., Frenkel, M. J., and Niblett, C. L. 1993. A polymerase chain-reaction method adapted for selective amplification and cloning of $3^{\prime}$ sequences of potyviral genomes application to Dasheen mosaic virus. J. Virol. Methods 41:9-20.

Peiró, A., Pallás, V., and Sánchez-Navarro, J. 2012. Simultaneous detection of eight viruses and two viroids affecting stone fruit trees by using a unique polyprobe. Eur. J. Plant Pathol. 132:469-475.
Revers, F., and Garcia, J. A. 2015. Molecular biology of potyviruses. Adv. Virus Res. 92:101-199.

Saade, M., Aparicio, F., Sanchez-Navarro, J. A., Herranz, M. C., Myrta, A., Di Terlizzi, B., and Pallas, V. 2000. Simultaneous detection of the three ilarviruses affecting stone fruit trees by nonisotopic molecular hybridization and multiplex reverse-transcription polymerase chain reaction. Phytopathology 90:1330-1336.

Saldarelli, P., Barbarossa, L., Grieco, F., and Gallitelli, D. 1996. Digoxigeninlabeled riboprobes applied to phytosanitary certification of tomato in Italy. Plant Dis. 80:1343-1346.

Sanchez-Navarro, J. A., Aparicio, F., Herranz, M. C., Minafra, A., Myrta, A., and Pallas, V. 2005. Simultaneous detection and identification of eight stone fruit viruses by one-step RT-PCR. Eur. J. Plant Pathol. 111:77-84.

Sanchez-Navarro, J. A., Aparicio, F., Rowhani, A., and Pallas, V. 1998. Comparative analysis of ELISA, nonradioactive molecular hybridization and PCR for the detection of prunus necrotic ringspot virus in herbaceous and Prunus hosts. Plant Pathol. 47:780-786.

Sanchez-Navarro, J. A., Canizares, M. C., Cano, E. A., and Pallas, V. 1999. Simultaneous detection of five carnation viruses by non-isotopic molecular hybridization. J. Virol. Methods 82:167-175.

Sanchez-Navarro, J. A., Cano, E. A., and Pallas, V. 1996. Non-radioactive molecular hybridization detection of carnation mottle virus in infected carnations and its comparison to serological and biological techniques. Plant Pathol. 45:375-382.

Scholthof, K.-B. G., Adkins, S., Czosnek, H., Palukaitis, P., Jacquot, E., Hohn, T., Hohn, B., Saunders, K., Candresse, T., Ahlquist, P., Hemenway, C., and Foster, G. D. 2011. Top 10 plant viruses in molecular plant pathology. Mol. Plant Pathol. 12:938-954.

Torchetti, E. M., Navarro, B., and Di Serio, F. 2012. A single polyprobe for detecting simultaneously eight pospiviroids infecting ornamentals and vegetables. J. Virol. Methods 186:141-146.

Wei, T., Pearson, M. N., Blohm, D., Nolte, M., and Armstrong, K. 2009. Development of a short oligonucleotide microarray for the detection and identification of multiple potyviruses. J. Virol. Methods 162:109-118.

Zamora-Macorra, E., Leobardo Ochoa-Martinez, D., Valdovinos-Ponce, G., Rojas-Martinez, R., Ramirez-Rojas, S., Sanchez-Navarro, J. A., Pallas, V., and Aparicio, F. 2015. Simultaneous detection of Clavibacter michiganensis subsp. michiganensis, Pepino mosaic virus and Mexican papita viroid by non-radioactive molecular hybridization using a unique polyprobe. Eur. J. Plant Pathol. 143:779-787.

Zhang, Z., Peng, S., Jiang, D., Pan, S., Wang, H., and Li, S. 2012. Development of a polyprobe for the simultaneous detection of four grapevine viroids in grapevine plants. Eur. J. Plant Pathol. 132:9-16.

Zheng, L., Rodoni, B. C., Gibbs, M. J., and Gibbs, A. J. 2010. A novel pair of universal primers for the detection of potyviruses. Plant Pathol. 59:211-220. 